\title{
Anticuerpos aviares: alternativa en producción y diagnóstico
}

\author{
Carmen E. Alarcón, Hernán Hurtado, Jaime E. Castellanos \\ Laboratorio de Neurociencias, Instituto Nacional de Salud, Bogotá D.C., Colombia.
}

\begin{abstract}
El uso de anticuerpos para investigación y diagnóstico se realiza desde hace varias décadas en todo el mundo. Normalmente, estos anticuerpos se obtienen a partir del suero de mamíferos (roedores, caprinos, equinos, etc.). De acuerdo con el tamaño del huésped, se pueden producir pequeñas o grandes cantidades de suero, haciendo siempre sangrias regulares para su recolección. En los últimos años, se han utilizado cada vez con mayor frecuencia anticuerpos purificados a partir de huevos de gallinas inmunizadas, los cuales presentan diferencias con los anticuerpos producidos en mamíferos en su estructura y características fisicoquímicas, pero, además, son una alternativa que disminuye el estrés e injuria al huésped y tiene alta productividad y facilidad para su recolección. Se ha informado el uso de estos anticuerpos aviares en ensayos inmunoquímicos, producción de conjugados y en terapéutica con un éxito similar al de los anticuerpos en mamíferos y a un costo menor. En este trabajo, se hace una revisión del tema y se plantean sus posibles usos tanto en investigación y diagnóstico, como en terapia.
\end{abstract}

Palabras clave: anticuerpos aviares, inmunoglobulina $Y$, inmunología.

Avian antibodies: an alternative in production and diagnosis

Research and diagnosis have used antibodies for many decades. These antibodies are obtained from several mammalian sera (rodents, caprines, equines, etc.), which are obtained through periodical bleeding and whose quantity depends on the host's size. During the last few years, eggs of immunized hens have often been used in order to get purified antibodies. Mammalian and hen antibodies have different structure and physicochemical features, but the latter have many advantages. Some of these advantages are: high productivity, easier collection and less stress and host injuries. Successful immunochemical essays, conjugate production and therapy using avian antibodies have been reported and they are cheaper than mammalian ones. The present work is a review on avian antibodies and their usefulness for research, diagnosis and therapy.

Key words: Avian antibodies, immunoglobulin $\mathrm{Y}$, immunology.

Los anticuerpos son proteínas que están presentes en el suero y en los tejidos de los vertebrados y se unen específicamente a moléculas extrañas (antígenos), generando una respuesta inmune (1). Los anticuerpos (Ac) policlonales son comúnmente producidos en mamíferos como conejos, hámsters, cabras, ovejas y caballos. Estos animales son buenos productores de anticuerpos pero presentan

\footnotetext{
Correspondencia:

Jaime Castellanos, Laboratorio de Neurociencias, Instituto Nacional de Salud, Bogotá, D.C., Colombia.

jcastellanos@hemagogus.ins.gov.co

Recibido: 20/06/00; aceptado: 22/09/00
}

algunas dificultades: las dos primeras especies mencionadas, que son las más usadas, generan cantidades reducidas de suero y las otras tres no son comúnmente usadas debido a la dificultad de hospedaje por su talla, alto costo de la dieta y difícil manipulación (2).

Además, en el caso de proteínas de mamífero altamente conservadas que se comportan como inmunógenos débiles, es difícil obtener una respuesta inmune humoral en animales como conejos y hámsters (3-7), así que una mayor distancia filogenética entre las especies involucradas ofrece mayor potencial para producir altos porcentajes de anticuerpos específicos 
contra estos antígenos. En consecuencia, se ha demostrado que la inmmunización de aves representa una herramienta poderosa para obtener anticuerpos contra esta clase de proteinas.

\section{Anticuerpos aviares}

Las aves han sido un modelo muy útil para la investigación básica en inmunología; de hecho, el término linfocitos $B$ se generó al conocerse que parte de la maduración de estas células ocurría en la bursa de Fabricius (presente únicamente en las aves); además, el sistema inmune de los mamíferos y de las aves mantienen muchas similitudes funcionales $(8,9)$. La bursa de Fabricius surge del tejido epitelial en la pared de la cloaca, germina y es infiltrada por células para formar el tejido linfoide característico. Ocho días antes del emplumaje, se detecta la primera inmunoglobulina (lg), la lgM, y varios días después aparecen las lgG (actualmente, llamadas IgY, yolk, yema) (9).

Las aves tienen un buen desarrollo del sistema inmune tanto humoral como celular y normalmente tienen grandes concentraciones de Ac en el suero y aún más en la yema del huevo $(10,11)$, pues las hembras transfieren anticuerpos sanguíneos a los huevos durante su período de maduración en el oviducto, y así proveen de una fuente de anticuerpos para los polluelos en caso de ocurrir una fecundación, de manera similar a como ocurre con el traspaso de los anticuerpos a través de la placenta en los mamíferos (12-14).

Las moléculas lgG de gallina tienen algunas características fisicoquímicas que las diferencian de las IgG de mamífero $(4,15)$. Por ejemplo, no interactúan con factores reumatoideos (12), no activan el sistema de complemento humano (15, 16), no se unen a la proteína A estafilocócica, no se unen a proteína $\mathrm{G}$ ni tampoco a los receptores Fc de las células de mamíferos, de tal manera que la probabilidad de dar falsos positivos en ensayos inmunológicos disminuye.

Desde hace más de una década, los huevos de gallina inmunizada fueron reconocidos como una excelente fuente de anticuerpos policlonales, pero no se había intensificado su uso debido a procedimientos de purificación dispendiosos e insatisfactorios (17). Hoy día, esta fuente de anticuerpos es una alternativa de producción a gran escala y bajo costo, si se tienen en cuenta todas sus bondades.

\section{Inmunoglobulinas en las aves y características fisicoquímicas de las $\lg \mathrm{Y}$}

Con base en estudios de antigenicidad de las cadenas pesadas $(\mathrm{H})$ de las lg de gallinas, algunos investigadores establecieron la existencia de dos clases: una macroglobulina y una globulina de bajo peso molecular, las cuales, sin suficientes datos fisicoquímicos, fueron relacionadas con la IgM y la IgG de mamífero, respectivamente (15, 18). Unos años más tarde, se encontró una tercera inmunoglobulina, la IgA (19). Después de un riguroso proceso de purificación, Leslie y Clem obtuvieron cadenas pesadas y livianas en proporciones de 75 y $25 \%$, respectivamente, con sus pesos moleculares de 70 y 22 kDa (15).

Comparando las características fisicoquímicas de estas moléculas extraidas de suero de gallina con las de las IgM y las IgG de mamífero y, teniendo en cuenta los estudios de antigenicidad, los autores confirmaron una leve similitud entre estos anticuerpos aviares y los de mamífero en términos de la arquitectura gruesa de la molécula y establecieron con seguridad que la denominada IgG de pollo no era igual a la lgG ni a ninguna otra Ig de mamífero, por lo que se le dio un nombre diferente, $\lg Y(15,20)$.

En la naturaleza, la lgY se encuentra en dos formas: una completa y otra trunca; ambas pueden coexistir en un individuo como sucede en algunas tortugas y aves anseriformes (patos) $(21,22)$. En otras especies, puede producirse una sola forma (las gallinas producen exclusivamente la forma completa) y algunas tortugas solamente producen la forma trunca (23).

La forma completa, llamada IgY, tiene una masa molecular de $180 \mathrm{kDa}$ y como todas las Ig de bajo peso molecular tiene dos cadenas $\mathrm{H}$ y dos cadenas livianas $(L)$. Las cadenas $H$ poseen una región variable $(\mathrm{V})$ y una región constante $(\mathrm{C})$ con cuatro dominios de inmunoglobulinas, razón que explica su gran tamaño $(18,24)$. La forma trunca tiene un peso molecular de $120 \mathrm{kDa}$, pues ha perdido los dos dominios carboxiterminales (Cv3 y Cv4) de las cadenas $H$, convirtiéndose en una 
molécula semejante a un fragmento $F\left(a b^{\prime}\right) 2$, por lo cual se sugiere darle el nombre de IgY(DFc) y se clasifica como una isoforma (18).

Los dominios Cv2 y Cv3 de las lgG de mamífero tienen un alto grado de similitud con las regiones Cv3 y Cv4 de las IgY, mientras que el dominio correspondiente a Cv2 está ausente $(18,20)$. Se cree que el dominio $\mathrm{Cv} 2$ de las IgY de los anfibios, reptiles y aves fue condensado para formar la región de la bisagra de las Ig en los vertebrados superiores, otorgándole a la molécula la característica de flexibilidad de las Ig (20). En consecuencia, la IgY carece de bisagra molecular, pero a su vez, entre los dominios Cv1-Cv2 y Cv2Cv3, la lgY posee gran cantidad de residuos de prolina y glicina que dan un suficiente grado de flexibilidad a la molécula para la óptima realización de sus funciones (24).

\section{Obtención de las IgY}

Normalmente, para la producción de suero hiperinmune en mamíferos, se hacen inoculaciones periódicas con el antígeno y el adyuvante; por ejemplo, cada semana durante uno a tres meses. Adicionalmente, se deben hacer sangrías para evaluar cualitativa y cuantitativamente el título de anticuerpos específicos contra el antígeno, lo que implica mayor trauma y estrés para el huésped. Por último, si se quiere obtener gran cantidad de suero, se necesita sacrificar al animal para recolectar toda la sangre por punción cardiaca.

La obtención de Ac a partir de yemas de los huevos de gallinas inmunizadas es un método menos invasor que presenta una alternativa interesante a los métodos convencionales de producción, pues omite las punciones intra-venosas necesarias para extraer suero y evaluar el título de anticuerpos. En este caso, la toma de muestras para el seguimiento del título se limita a la simple, diaria y continua recolección de los huevos de la gallina inmunizada. La producción de Ac a gran escala en gallinas está asociada, además, a ventajas de tipo económico. Aunque una gallina tiene aproximadamente el mismo costo de un conejo, la primera representa mayor economía, ya que se necesitan menos gallinas si se usan sus huevos como fuente de Ac. Se ha demostrado que la cantidad de IgY específica contra el antígeno de interés, presente en las yemas producidas en un mes, es 18 veces mayor que la IgG producida en un conejo con una afinidad similar.

La literatura informa de varios métodos de purificación de anticuerpos $\lg \mathrm{Y}(2,10,11,13,14)$ y todos convergen en cuatro pasos fundamentales: remoción total de la albúmina, liberación de la yema de su membrana, extracción de las lipoproteínas y lípidos de la yema y aislamiento de las inmunoglobulinas $(\lg Y)$. Se han ensayado muchos métodos, pero, en general, todos deben cumplir con los requisitos de rendimiento, pureza, conservación de la actividad del anticuerpo y bajo costo de los procedimientos utilizados.

Los dos primeros pasos son procesos físicos que sólo requieren de una sencilla manipulación para conseguir la liberación de la mayor cantidad de yema libre de albúmina. La yema de huevo está compuesta principalmente por gránulos de lipoproteínas y fosvitinas suspendidos en una fracción soluble de levitinas y lipoproteínas de baja densidad $(14,25)$. El tercer paso involucrado en la metodología es la separación de las proteínas (levitinas) de las lipoproteínas (lipovitelinas) y el resto de lípidos de la yema mediante un método de extracción lipídica. Normalmente, se usa un detergente o un solvente orgánico que solubilice los lípidos y, a su vez, facilite la posterior purificación de las proteínas.

La optimización de la purificación depende mucho de la elección del método que se emplee para evadir la molesta tendencia de las lgY a precipitar junto con los lípidos. Los trabajos informados usan métodos simples o combinaciones de éstos, que involucran mezclas con solventes orgánicos y centrifugación para eliminar los lípidos $(5,13)$, prolongados tiempos de centrifugación a alta velocidad $(14,26)$, adición de sulfato de dextrán y centrifugación $(11,26)$, tratamiento con suspensiones acuosas de ftalato de hidroxi-propil-metil celulosa y etanol $(27,28)$, remoción de fosfoproteínas y lipoproteínas por precipitación con $3 \%$ de polietilenglicol y baja velocidad de centrifugación, o por congelación y descongelación de la yema diluida y larga centrifugación a baja velocidad y, luego, filtración $(10,29,28)$, o mediante 
el uso de cromatografía de interacción hidrofóbica (17). Para la purificación de las IgY como tal, se han usado tambien varios métodos: precipitación por tratamiento crioetanólico, polietilenglicol al $12 \%(2,26,28,30)$, adición de sales como el sulfato de dextrán $(14,26)$, el sulfato de sodio (31), el sulfato de amonio $(10,11)$, adición de ácido caprílico, seguidos por centrifugación o separación por tamaños mediante ultrafiltración, filtración en gel (17) o separación por cromatografía de intercambio iónico usando resinas aniónicas (29) y también cromatografía de afinidad (32). Excepto para las cromatografías, el principio de estos métodos consiste en que el compuesto 'captura' gran cantidad del agua del tampón, para dejar las zonas hidrofóbicas de las proteínas disponibles para interactuar entre sí, lo cual genera una molécula compleja que fácilmente se puede precipitar.

Estudios comparativos en términos de rendimiento, pureza, facilidad de uso e inmunoactividad entre los diferentes métodos de extracción de $\lg Y$ o combinaciones de ellos, dejan ver que ningún procedimiento tiene efectos adversos sobre la actividad de las IgY. Sin embargo, los procedimientos más populares son los de precipitación, quizás por el bajo costo. Debido al auge y a las ventajas para el uso de las IgY, en la actualidad se encuentran en el mercado reactivos comerciales que logran procesos de purificación en corto tiempo y con alta pureza, hasta de $95 \%$.

\section{Algunas aplicaciones de las IgY}

Las $\lg Y$ se han aplicado en inmunodiagnóstico, investigación e imnunoterapia. Un huevo contiene entre 3 y $5 \mathrm{mg}$ de IgY por cada mililitro de yema (en total 70-100 mg de lgY total según el tamaño del huevo). De ese total, de 2 a $10 \%$ es $\lg Y$ generado contra un antígeno específico en gallinas inmunizadas (3). Esta gran cantidad de Ac, muy bien empacados y muy estables, facilita su producción y aplicación en la detección de antígenos para diagnóstico en medicina humana y veterinaria, como también en producción de conjugados $(14,28)$.

Por ejemplo, se han producido Ac contra proteínas de mamíferos altamente conservadas y otras moléculas como el factor inductor de hipoxia (5), contra péptidos de la proteína MPT40 de
Mycobacterium tuberculosis (33), contra la 1,25dihidroxivitamina $\mathrm{D}(31)$, la activina $A$, la prolactina (11), la subunidad alfa de los receptores de insulina (34) y el antígeno celular nuclear de proliferación, normalmente poco antigénico (9). Las IgY como primero o segundo anticuerpo, se han usado en radioinmunoensayo e inmunoelectroforesis (14) y como anticuerpo secundario en Western blots, en citometría de flujo, inmunoprecipitación y ELISA. Adicionalmente, las lgY se usan frecuentemente en ensayos de detección del análogo al antígeno presente en otras especies, pues por la distancia filogenética, éstos reconocen más fácilmente la misma proteína en diferentes especies (28). Algunos ejemplos del uso de lgY en inmunoterapia se han dirigido hacia la protección de infecciones entéricas producidas por bacterias $(10,14,27)$. Se ha logrado prevenir la morbilidad y mortalidad de cerdos neonatos, administrando por vía oral lgY contra proteínas de la fimbria de Escherichia coli enterotoxigénica (30). En otro estudio se usaron enjuagues bucales con $\lg Y$ anti-Streptococcus mutans, uno de los principales agentes etiológicos de la caries, para establecer inmunidad pasiva y proteger animales de laboratorio de la aparición de la enfermedad (35). Anticuerpos IgY contra Porphyromonas gingivalis también han sido producidos y caracterizados con el ánimo de ser usados en inmunodiagnóstico de la enfermedad periodontal (36).

Son de particular interés las recientes propuestas para establecer la producción de sueros antiofídicos utilizando anticuerpos aviares. Carroll y colaboradores (37) inmunizaron gallinas con venenos de Crotalus y purificaron IgY antiveneno con alto grado de rendimiento, pureza y potencia. Estas características y la inhabilidad de las IgY para activar el complemento humano hacen de estos anticuerpos una atractiva alternativa de producción de este tipo de biológicos. Con similares resultados, se obtuvieron IgY antivenenos de Bothrops y Crotalus que bloquearon la actividad hemolítica dependiente de fosfolipasa A2 y la actividad hemorrágica del veneno de Bothrops, neutralizando eficazmente su letalidad (38).

En conclusión, las técnicas clásicas de inmunoquímica e incluso la inmunoterapia, se 
están beneficiando cada vez más del uso de anticuerpos obtenidos a partir de huevos de gallinas inmunizadas, pues han demostrado ser un excelente sustrato para su producción tanto a pequeña como a gran escala. En un futuro no muy lejano, las ventajas económicas y éticas pueden dejar en el olvido al conejo, hasta ahora rey de los policlonales.

\section{Referencias}

1. Elgert KE. Immunology. Understanding the immune system. New York: Wiley-Liss, Inc.; 1996. p.47-65.

2. Polson A, Von Wechmar MB, Van Regenmortel MH. Isolation of viral lgY antibodies from yolks of immunized hens. Immunol Comm 1980;9:475-93.

3. Haak-Frendscho M. Eggstract. Promega Notes Magazine 1995;46:11-3

4. Kronwall G, Seal US, Finstad J, Williams RC. Philogenetic insight into evolution of mammalian FC fragment of $\mathrm{G}$ globulin using staphylococcal protein Am J Immunol 1970;104:140-7.

5. Camenisch G, Tini M, Chilov D, Kvietikova I, Srinivas V, Caro J, et al. General applicability of IgY immunoglobulins raised against the hypoxia-inducible factor $1 \mathrm{a}$. FASEB J 1999;13:81-8.

6. Murata T, Saito S, Shiozaki M, Lu R Z, Eto $\mathbf{Y}$, Funaba $M$, et al. Anti-activin A antibody (IgY) specifically neutralizes various activin $A$ activities. Soc Exp Biol Med 1996;211:100-7.

7. Gassmann M, Thömmes $\mathbf{P}$, Weiser $\mathbf{T}$, Hubscher $\mathbf{U}$. Efficient production of chicken egg yolk antibodies against a conserved mammalian protein. FASEB J 1990; 4:2528-32.

8. Funk PE, Thompson C. Current concepts in chicken B cell development. Curr Top Microbiol Immunol 1996; 212:1728.

9. Vainio O, Imhof BA. The immunology and developmental biology of the chicken. Immunol Today 1995; 16:36570.

10. Farrelly CO, Branton, Wanke CA. Oral ingestion of egg yolk immunoglobulin from hens immunized with an enterotoxigenic Escherichia coli strain prevents diarrhea in rabbits challenged with the same strain. Infect Immun 1992;60:2593-7.

11. Schmidt P, Erhard M H, Schams D, Hafner A, Folger S, Lösch U. Chicken egg antibodies for immunohistochemical labeling of growth hormone and prolactin in bovine pituitary gland. J Histochem 1993;41:1441-6.

12. Anders L, Sjöquist J. Chicken antibodies: a tool to avoid false positive results by rheumatoid factor in latex fixation tests. J Immunol Meth 1988;108:205-8.
13. Svendsen BL, Crowley A, Stodulski G, Hau J. Antibody production in rabbits and chickens immunized with humman IgG. A comparison of titre and avidy development in rabbit serum, chicken serum and egg yolk using three different adjuvants. J Immunol Meth 1996;191:113-20.

14. Jensenius JC, Andersen I, Hau J, Crone M, Koch C. Eggs: conveniently packaged antibodies. Methods for purification of yolk IgG. J Immunol Meths 1981;46:63-8.

15. Leslie GA, Clem LW. Philogeny of immunoglobulin structure and function. III. Immunoglobulins of the chicken. J Exp Med 1969;130:1337-52.

16. Hädge D, Ambrosius H. Evolution of low molecular weight immunoglobulins. IV. IgY-like immunoglobulins of birds, reptiles and amphibians. Precursors of mammalian IgA. Mol Immunol 1984;21:699-707.

17. Hassı A, Aspöck H. Purification of egg yolk immunoglobulins. A two-step procedure using hydrophobic interaction chromatography and gel filtration. $\mathrm{J}$ Immunol Meth 1988;110:225-8.

18. Magor KE, Higgins DA, Middleton DL, Warr GW. One gene encodes the heavy chains for three different forms of IgY in the duck. J Immunol 1994;153:5549-55.

19. Antti M. Chicken IgA H chains. Implications concerning the evolution of H chain genes. J Immunol 1992;149:85561.

20. Parvari R, Avivi A, Lentner F, Ziv E, Tel-Or S, Burstein $Y$, et al. Chicken immunoglobulin gamma-heavy chains: limited $V h$ gene repertoire, combinatorial diversification by $D$ gene segments and evolution of the heavy chain locus. EMBO J 1988;7:739-44.

21. Howard GM. Duck immunoglobulins. I. Structural studies on a $5,7 \mathrm{~S}$ and $7,8 \mathrm{~S}$ gamma globulins. J Immunol 1967; 98:811-9.

22. Magor KE, Warr GW, Middleton D, Wilson MR, Higgins DA. Structural relationship between the two IgY of the duck, Anas platyrhynchos: molecular genetic evidence. J Immunol 1992;149:2627-33.

23. Gerrie LA, William C. Phylogeny of immunoglobulin structure and function. VI.17S, 7,5S anti-DNP of the turtle, Pseudamys scripta. J Immunol 1972;108:1656-64.

24. Warr GW, Magor KE, Higgins DA. IgY: clues to the origins of modern antibodies. Immunol Today 1995; $16: 392-8$

25. Burley MW, Cook WH. Isolation and composition of avian yolk granules and their constituents alpha and betalipovitellins. Can J Biochem Physiol 1961;39:1295-302.

26. Akita EM, Nakai S. Comparison of four purification methods for the production of immunoglobulins from eggs laid by hens immunized with an enterotoxigenic $E$. coli strain. J Immunol Meths 1993;160:207-14.

27. Ikemori M, Peralta R, Yokohama H, Kodama Y. Protection of neonatal calves against fatal enteric 
colibacillosis by administration of egg yolk powder from hens immunized with K99-piliated enterotoxigenic Escherichia coli. Am J Vet Res 1992;53:2005-8.

28. Svendsen L, Crowley A, Ostergaard LH, Stodulsky G, Hau J. Development and comparison of purification strategies for chicken antibodies from egg yolk. Lab Anim Sci 1995;45:89-93.

29. Sean BC, Stollar BD. Antibodies to calf thymus RNA polymerase II from egg yolks of immunized hens. J Biol Chem 1983;258:24-6.

30. Yokohama H, Peralta R, Díaz R, Sendo S, Ikemori Y, Kodama $Y$. Passive protective of chiken egg yolk immunoglobulins against experimental enterotoxigenic Escherichia coli infection in neonatal piglets. Infect Immun 1992;60:998-1007.

31. Bauwens RM, Kint JA, Devos MP, Van Brussel KA, De Leenher AP. Production, purification and characterization of antibodies to 1.25-dihidroxyvitamin $D$ raised in chicken egg yolk. Clin Chem Acta 1987; 170:37-44.

32. Yokohama H, Peralta R, Sendo S, Ikemori Y. Detection of passage and absorption of chiken egg yolks immunoglobulins in the gastrointestinal tract of pigs by use of enzyme-linked immunosorbent assay and fluorescent antibody testing. Am J Vet Res 1993;54:86772.
33. Crosby MJ, Díaz D, Orozco DO, Garnica MA, Hernandez M, Reyes J. Alternativas de la inmunologia como herramienta de investigación y diagnóstico: generación, aislamiento y purificación de anticuerpos específicos en huevo de gallina. Diógenes 1994;1:137-49.

34. Chung-Seog S, Ju-Hyun Y, Dong-Hoon B, Hester PY, Ki-Hang K. Antibodies to the a-subunit of insulin receptor from eggs of immunized hens. J Immunol 1985; 135:3354-9.

35. Hatta H, Tsuda K, Ozeki M, Yomamoto T, Otake S, Hirasawa $\mathrm{M}$, et al. Passive immunization against dental plaque formation in humans: effect of a mouth rinse containing egg yolk antibodies (IgY) specific to Streptococus mutans. Caries Res 1997;31:268-74.

36. Cely A, Martínez DM. Producción y caracterización inmunoquímica de una $\lg Y$ anti-Porfiromonas gingivalis (tesis). Bogotá: Universidad El Bosque; 1998.

37. Carroll SB, Thalley BS Theakston RD, Laing G. Comparison of the purity and efficacy of affinity purified avian antivenoms with commercial equine crotalid antivenoms. Toxicon 1992;30:1017-25.

38. Almeida CM, Kanashiro MM, Rangel FB, Mata MF, Kipnis TL, Da Silva WD. Development of snake antivenom antibodies in chickens and their purification from yolk. Vet Rec 1998;143:57-84. 